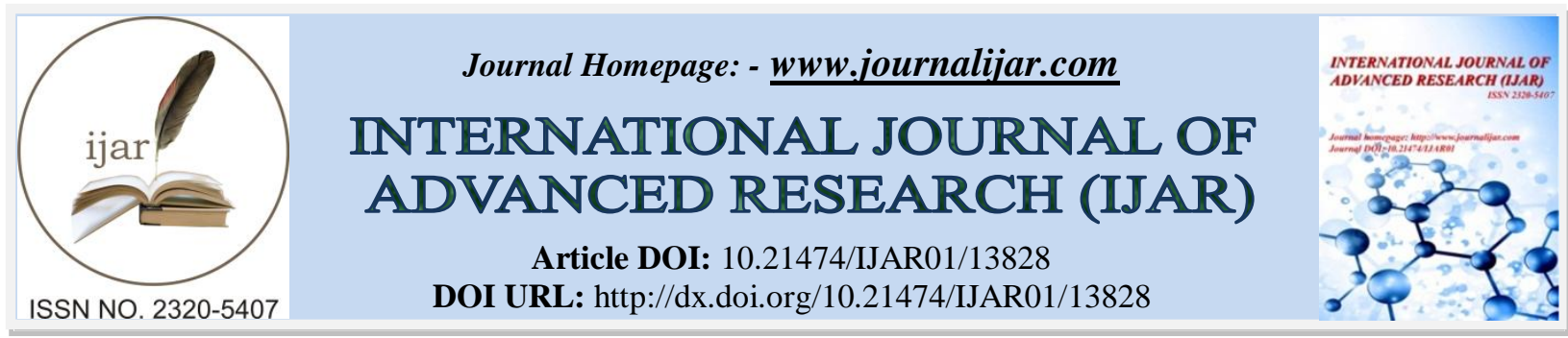

RESEARCH ARTICLE

\title{
A RARE PERIPHERAL ODONTOGENIC KERATOCYST IN FLOOR OF MOUTH: A CASE REPORT
}

\section{Dr. Jyotirmay Chakrawarty ${ }^{1}$, Dr. Vishal Bamniya ${ }^{2}$, Dr. Ankit Goyal ${ }^{3}$, Dr. Sakshi Chokhandre ${ }^{4}$ and Dr. Mayank Vagadia ${ }^{5}$}

1. Resident Surgical Officer, Dept of Oral and Maxillofacial Surgery, GDC Indore.

2. Postgraduate Resident, Dept of Oral Medicine and Radiology, GDC Indore.

3. Postgraduate Student, Dept of Oral Pathology and Microbiology, GDC Indore.

4. Postgraduate Student, Dept of Periodontology, GDC Indore.

5. Postgraduate Student, Dept of Prosthodontics, GDC Indore.

\section{Manuscript Info}

Manuscript History

Received: 29 September 2021

Final Accepted: 31 October 2021

Published: November 2021

\section{Abstract}

Copy Right, IJAR, 2021,. All rights reserved.

\section{Introduction:-}

Odontogenic Keratocysts(also termed as Keratocystic Odontogenic tumours) are one of the most common odontogenic tumours present in the oral cavity. First described by Philipsen in 1956, OKCs account for about 10\% of all jaw cysts. According to WHO, they represent odontogenic tumours originating from the epithelium only without the involvement of ectomesenchyme. It is generally considered an intraosseous lesion, in rare instances the odontogenic keratocyst may occur peripherally. To our knowledge, there are only 20 cases of peripheral odontogenic keratocyst thus far reported in the English language literature.

Here, we present a case of soft tissue counterpart of an Odontogenic keratocyst occurring in the floor of mouth of a 70 year old adult.

\section{Case Report}

A 70 year old male patient reported to the department of Oral and Maxillofacial Surgery with a chief complaint of swelling in left side of the floor of mouth since 3 months. The patient was aware of the lesion but as it was asymptomatic decided not to get it treated until the size started increasing and he started developing difficulty in speaking. The swelling gradually increased in size from pea size to the present size. The patient reported no history of trauma or any other debilitating medical conditions.

The extraoral examination was non contributory. Intraoral examination(fig1 and 2) revealed a submucosal swelling around 2-3 cms in size involving the left side of the floor of mouth, which was covered by normal mucosa and fluctuant on palpation, and what appeared to be purulent exudate was expressed from it. As the patient was edentulous no involvement of teeth could be traced. An Orthopantomogram was advised, which did not reveal any significant abnormality. Next, as the lesion was involving the soft tissue a MRI face and neck was ordered to find out the extent of the lesion.

Corresponding Author:- Dr. Jyotirmay Chakrawarty

Address:- Resident Surgical Officer , Dept of Oral and Maxillofacial Surgery, GDC Indore. 

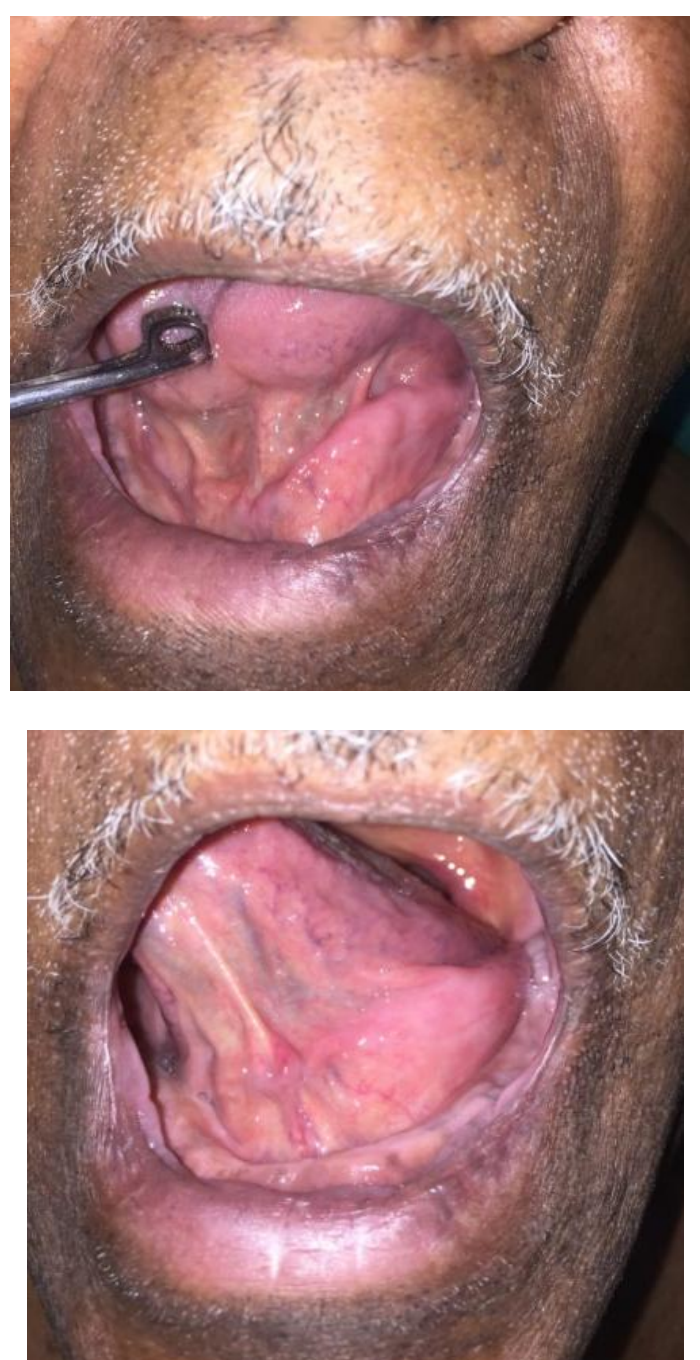

Fig 1 and 2:- Intraoral lesion in the floor of mouth.

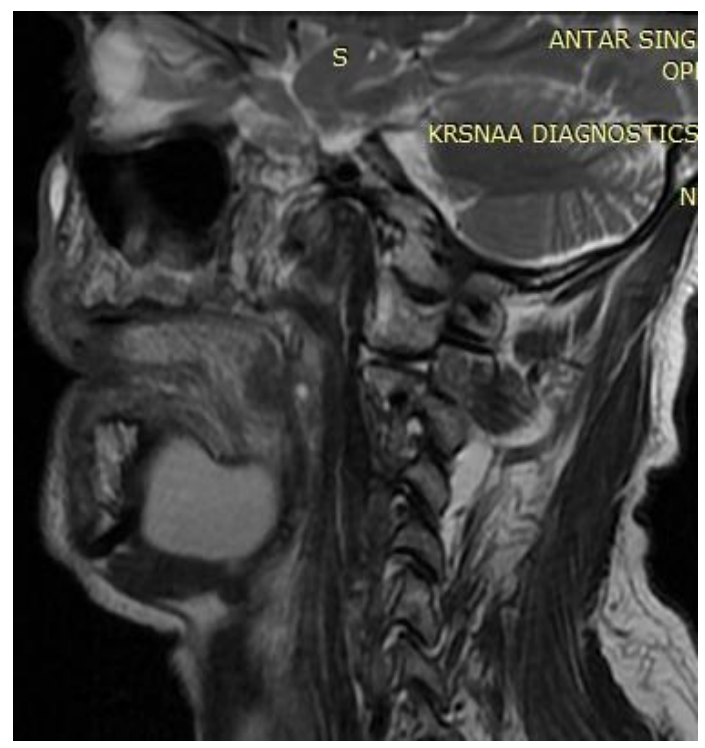




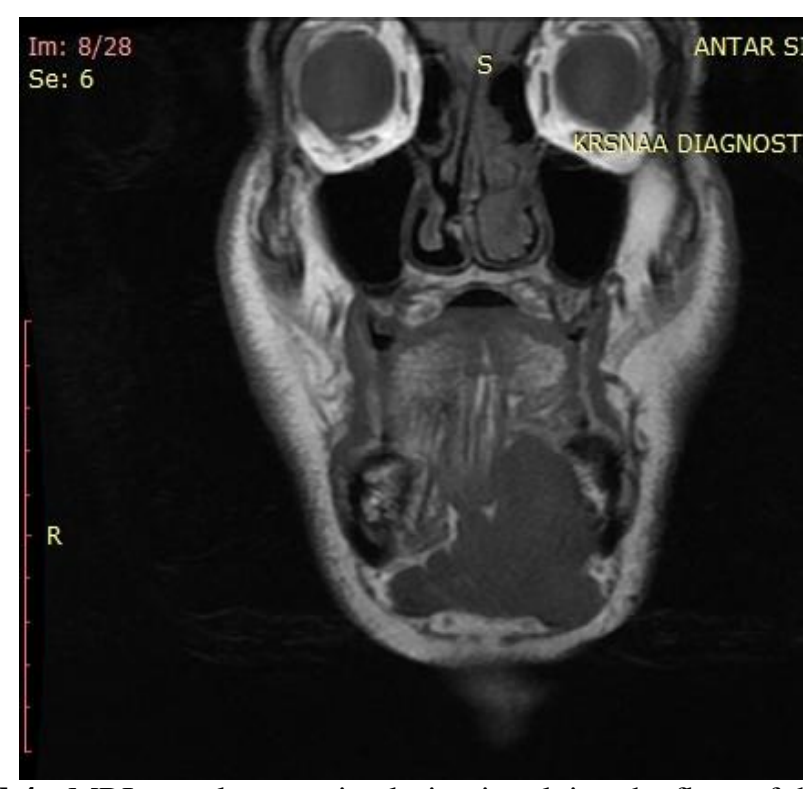

Fig3 and 4:- MRI reveals extensive lesion involving the floor of the mouth.

On the basis of above findings, a cystic lesion of the floor of the mouth was suspected and a surgical plan of surgical excision and curettage was made.

\section{Surgical Technique}

Under nasotracheal intubation along with General anaesthesia in the operating room, a crestal incision was given and lingual flap was elevated. After layerwise blunt dissection, the cystic mass was exposed, which was carefully dissected from all the surrounding tissues and removed in toto and placed in saline-formaline mixture and sent for histopathological examination. After thorough curettage taking care of the anatomical landmarks, haemostasis was achieved and primary closure done with 3-0 Vicryl multifilament sutures.

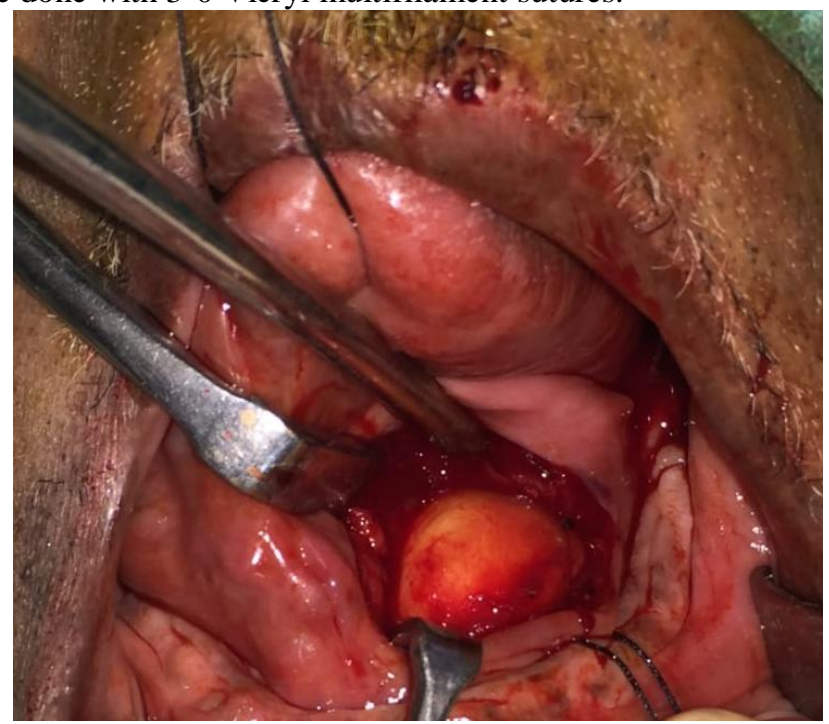

Fig 3:- Surgical exposure of the lesion. 


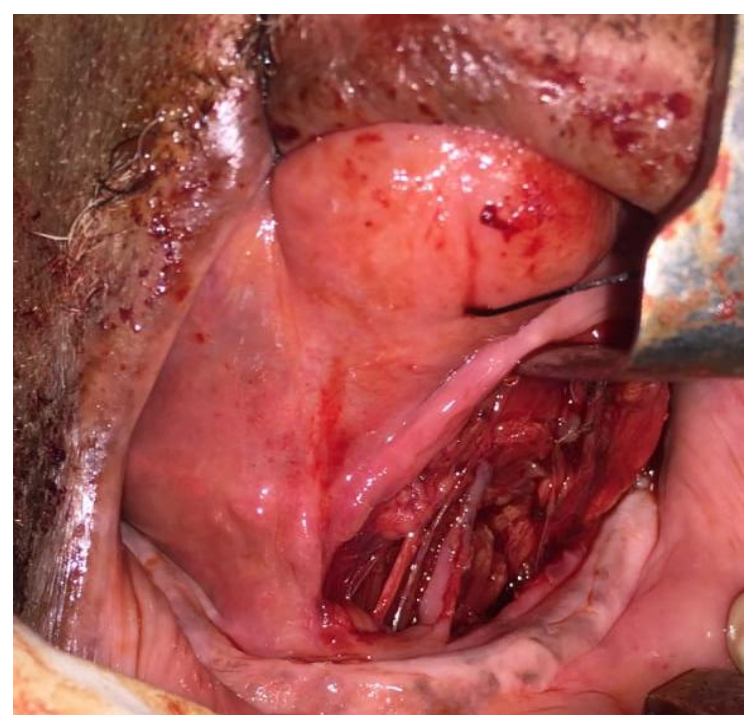

Fig 4:- Cavity after removing the lesion.

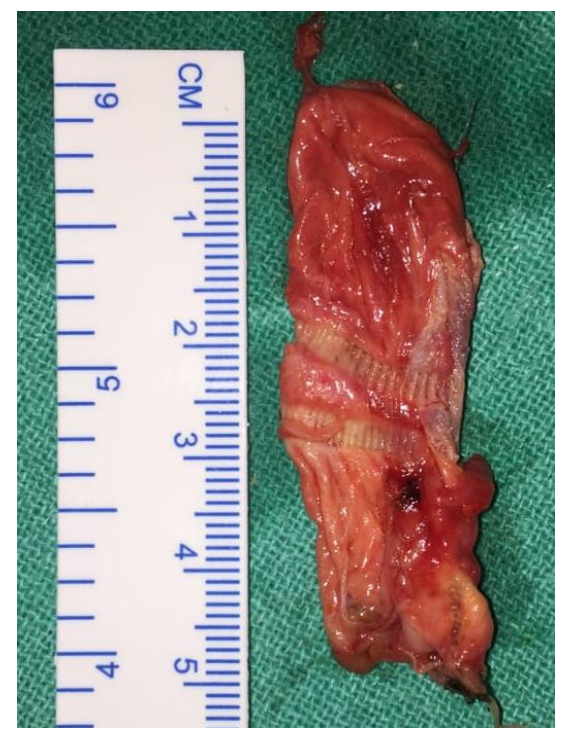

Fig 5:- Specimen sent for histopathology.

Histopathological Examination

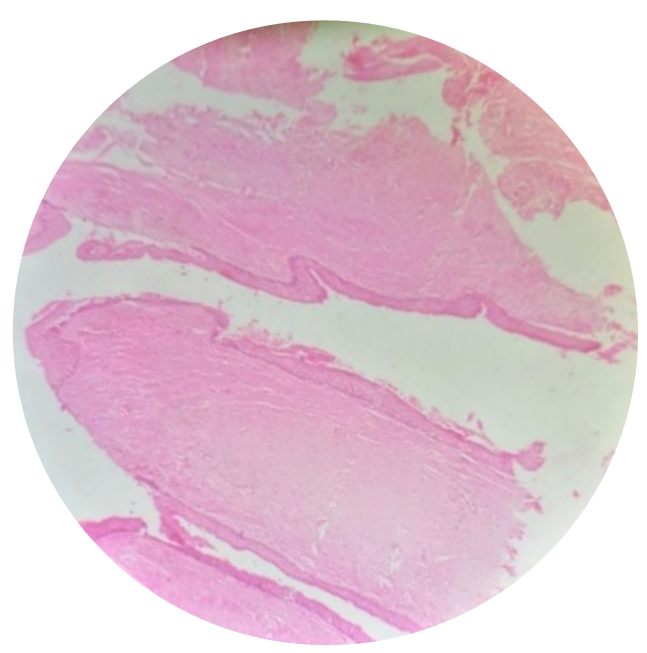


Fig 6:- H\&E stained section revealed the presence of 8-12 layered, stratified squamous cystic epithelium with surface corrugations surrounding a lumen. The epithelium is of even thickness and lacks rete ridges with tall columnar basal cells that resembles a tombstone.Few keratin flecks are also noted in the lumen.

The underlying stroma is densely fibrillar composed of collagen fibres arranged in bundles interspersed with few plump fibroblasts. The connective tissue is richly vascular with many dilated endothelial cell lined capillaries.

Overall features suggestive of “Odontogenic Keratocyst”.

\section{Discussion:-}

The term Odontogenic keratocyst was first used by Philipsen in 1956, while Hansen and Pindborg described the clinical presentation of this cyst in 1963. Histologically, it has been defined as 'A cyst derived from the remnants of dental lamina, with a biological behaviour similar to a benign neoplasm with a distinctive lining of 6-10 cells in thickness and that exhibits a basal cell layer of palisaded cells and a surface of corrugated parakeratin'.

They are unique odontogenic lesions that have a tendency to behave aggressively, which recur spontaneously and are sometimes associated with Nevoid basal cell carcinoma ${ }^{2,3}$, due to which in 1967 Toller suggested that these cysts must be considered as benign cystic neoplasms ${ }^{1,10}$. In 1962 Pindborg, Henriksen and Philipsen gave the following histopathologic criteria for characterizing this lesion

(1) The lining epithelium is uniform in thickness and usually very thin with little or no evidence of rete ridges

(2) there is a well defined basal cell layer, whose component cells are cuboidal or columnar in shape and often in a palisaded arrangement

3) there is a thin spinous cell layer which often shows a direct transition from the basal cell layer

4) the cells of the spinous cell layer frequently exhibit intracellular edema

5) the keratin layer is often corrugated

6) keratinization is predominantly parakeratotic, but it may be orthokeratotic

7) the fibrous cyst wall is generally thin and usually uninflamed. ${ }^{7}$

Subsequently several authors observed that the orthokeratinized variant be differentiated from the parakeratinised version as it has a limited growth potential, low recurrence rate, and no association with nevoid basal cell carcinoma syndrome. ${ }^{1,3,5}$ Also ,Brannon et al. reported that keratocysts sometimes(in a small percentage of cases) exhibit both parakeratin and orthokeratin and these cysts should be therefore, be treated as parakeratinized odontogenic keratocysts because they have a tendency for recurrence less than the purely parakeratinized but more than the orthokeratinized variants. ${ }^{11}$ As of now, the parakeratinized variant is referred to as 'odontogenic keratocyst,' whereas the orthokeratinized variant is referred to as "orthokeratinized odontogenic cyst" to make a difference between the two entities.

Extraosseous equivalents have been described in the literature for several central odontogenic tumors. The most common peripherally occurring odontogenic tumor is the Peripheral Ameloblastoma. Peripheral counterparts have also been described for AOT(Adenomatoid odontogenic tumor), CEOT(calcifying epithelial odontogenic tumor), odontogenic fibroma, and granular cell ameloblastic fibroma. ${ }^{8}$ In addition, a peripheral variant has been described for the calcifying odontogenic cyst, considered by some to be a tumor. ${ }^{9}$

In our case, the cyst associated with an edentulous mandible did not show an aggressive course and rather just increased in size by causing local involvement giving us a suspicion of Orthokeratinised Odontogenic cyst but the histopathological examination revealed a parakeratinised epithelial lining and gave the typical features of Odontogenic Keratocyst and hence we prefer to use the term of 'Peripheral Odontogenic keratocyst' for the particular lesion.

\section{Conclusion:-}

In general, peripheral odontogenic cysts and tumors follow a benign, nonaggressive clinical course and so is the scenario with the case described above. The lesion observed on the floor of the mouth was an encapsulated lesion with no recurrence. It is imperative that all the dental professionals be aware of peripheral occurrence of these types of lesions which will refine the services offered to the patients and keep them free of any kind of morbidity. 


\section{References:-}

1. Rajendran R, Sivapathasundaram B; Shafers Textbook of Oral Pathology, $7^{\text {th }}$ edition , India: Elsevier;2012.

2. Neville BW, Damm DD, Allen CM, Bouqout JE. Oral and maxillofacial pathology. 2nd ed. Philadelphia: Saunders; 2002.

3. Dayan D, Buchner A, Gorsky M, Harel-Raviv M. The peripheral odontogenic keratocyst. Int J Oral Maxillofac Surg 1988;17: 81-3.

4. Ide F, Tetsuo S, Horie N. Peripheral odontogenic keratocyst: a report of two cases. J Periodontol 2002;73:107981.

5. Buchner A, Hansen LS. The histomorphologic spectrum of the gingival cyst in the adult. Oral Surg Oral Med Oral Pathol Oral Radiol Endod 1979;48(6):532-9.

6. Philipsen HP. Om keratocyster (kolesteatomer) i kaeberne. Tandlaegebladet 1956;60:963-80.

7. Pindborg JJ, Philipsen HP, Henriksen J. Studies on odontogenic cyst epithelium. In: Sognnaes RF, editor. Fundamentals of keratinization. Washington (DC): American Association for the Advancement of Science; 1962. p. 151-60.

8. Buchner A, Sciubba JJ. Peripheral epithelial odontogenic tumors: a review. Oral Surg Oral Med Oral Pathol Oral Radiol Endod 1987;63(6):688-97.

9. Horowitz I, Hirshberg A, Dayan D. Peripheral ameloblastoma- a clinical dilemma in gingival lesions. J Clin Periodontol 1987; 14(6):366-9.

10. Toller PA. Origin and growth of cysts of the jaws. Ann Roy Coll Surg 1967;40:306-36.

11. Brannon RB. The odontogenic keratocyst. A clinicopathologic study of 312 cases. Part II. Histologic features. Oral Surg Oral Med Oral Pathol Oral Radiol Endod 1977;43(2):233-55. 